\title{
The Egyptian formula a new formula for prediction of fetal birth weight using liver volume measured by three-dimensional ultrasound (VOCAL system)
}

\begin{abstract}
Introduction: Normal fetal growth is essential for healthy pregnancy. Fetal abdominal circumference measurement is the cornerstone in determination of fetal growth. Fetal liver contributes to the majority of the abdominal circumference, and estimation of its volume has been of interest, especially in cases of growth restriction as hepatic glycogen stores are severely depleted.
\end{abstract}

Aim: To predict fetal growth restriction using the fetal liver volume calculated in the second trimester of pregnancy by $3 \mathrm{D}$ ultrasound.

Study design: Multi-center case series study.

Patients \& methods: Three hundred qualified pregnant women attending for 20 weeks anomaly scan had fetal liver volume, head circumference, abdominal circumference and femur length measured using three-dimensional VOCAL system then the same measurements were repeated between 34 and 40weeks. All cases were followed until delivery and babies weighed in the first 24hours. The data were recorded and statistically analyzed.

Results: Statistically significant positive correlation between second trimester fetal liver volume and birth-weight, while other second trimester measurements didn't show this significant correlation. A significant correlation was found between all third trimester measurements and birth weight.

Conclusion: Second trimester liver volume measurement is superior to other second trimester measurements in predicting fetal birth weight.

Keywords: three-dimensional ultrasound, fetal growth, biometry
Volume 4 Issue 2 - 2017

\author{
Haitham Torky, ' Moustafa Hegab, ${ }^{2}$ Mourad \\ Kamel, ${ }^{2}$ Mohammad Salah Eldin, ${ }^{2}$ Hossam \\ Eldin Hussein, ${ }^{2}$ Diaa Abdelhalim ${ }^{3}$ \\ 'Department of Obstetrics \& Gynecology, 6th October \\ University, Egypt \\ ${ }^{2}$ Department of Obstetrics \& Gynecology,Al-Azhar University, \\ Egypt \\ ${ }^{3}$ Department of Obstetrics \& Gynecology,Al-Galaa Teaching \\ Hospital, Egypt
}

Correspondence: Haitham Torky, Department of Obstetrics and Gynecology, October 6th University, Cairo, Egypt, Tel +201001230161 , Fax No +20225240066,

Email haithamtorky@yahoo.com

Received: November 15, 2016 | Published: January 19, 2017

\section{Introduction}

Normal fetal growth is an essential factor of a healthy pregnancy and off-spring, as abnormal fetal growth especially fetal growth restriction has been associated with the development of some diseases latter in life, for example, cardiovascular diseases and type 2 diabetes. The definition of small for gestational age is an estimated fetal weight (EFW) lying below the $10^{\text {th }}$ percentile of a particular reference for a given gestational week. ${ }^{2}$ Fetal abdominal circumference measurement is the cornerstone in ultrasonic determination of fetal weight and growth, ${ }^{3}$ and as fetal liver contributes to the majority of the abdominal circumference estimation its volume has been of interest, especially in cases of growth restriction as hepatic glycogen stores are severely depleted in this condition in humans and rats. ${ }^{4}$ Vintzileos and co-workers ${ }^{5}$ reported that reduced abdominal circumference was mainly due to reduced liver size. However, precise and noninvasive measurement of fetal liver volume is not easily done by twodimensional ultrasound. This limitation has been overcome by the use of quantitative volume assessment by three-dimensional ultrasound which enabled the antenatal prediction of fetuses with growth restriction. ${ }^{6}$ The primary objective of the current study was to predict fetal growth restriction using the fetal liver volume calculated in the second trimester of pregnancy, using 3D ultrasound. The secondary objective was develop to a new formula to estimate fetal weight using the fetal liver volume in the prediction of fetal growth restriction.

\section{Patients and methods}

This longitudinal case series multi-center study was conducted at the fetal medicine unit of Al-Azhar University, $6^{\text {th }}$ October University and Al-Galaa Teaching Hospital from December 2011 till August 2014. The study has been approved by the ethical committee of AlAzhar University. All patients signed an informed consent. Three hundred and twenty four women were recruited for this study of which three hundred women had two technically acceptable ultrasound liver recordings which was considered so if the entire contour of the liver could be manually outlined and if this parameter was not fulfilled, a new volume data set was obtained. The remaining twenty-four women either had unacceptable liver recording, failed to attend for the $2^{\text {nd }}$ scan or delivered outside the hospitals, hence were not included in the study. All cases participating in the study were Egyptians between the age of 18 and 40, primigravid as and carrying a singleton pregnancy attending the antenatal clinics of the three hospitals for ante natal care, multi-paras and those with multiple pregnancies were excluded from the study. Fetal age determination was estimated from the first day of the last menstrual period and confirmed by a first-trimester dating ultrasound scan done between 10 and 12 weeks. All cases were subjected to two scans the first one between 20 and 28 weeks and the second between 34 and 40weeks using a GE Voluson 730 PRO ultrasound system provided with the Virtual Organ Computeraided AnaLysis (VOCAL) software. A 5-MHz trans-abdominal 3D 
transducer was used, in addition to, measuring the actual baby's weight within 24 hours after birth as all deliveries were performed in our teaching hospitals.

In each scan the head circumference (HC), abdominal circumference (AC) and femur length (FL) were measured and recorded. VOCAL was used to calculate the fetal liver volume (LV) (Figure 1). A cross section of the fetal liver was obtained in the same plane used to measure the abdominal circumference. Then, the 3D volume box was opened and adjusted to the cross section of the fetal abdomen (Region of Interest) and the fetal abdomen scanned to obtain a 3D data set. The sweep angle was set at $90^{\circ}$. Volume acquisition lasted less than $1 \mathrm{~min}$. This produced a multiplanar image showing the fetal abdomen in three planes (transverse, longitudinal and coronal). VOCAL software was then used with a thirty degree rotational method obtaining a sequence of six sections of the fetal liver around a fixed axis. Then, the borders of the fetal liver were traced manually to complete its circumference. After finishing the six sections, the software automatically displays a 3D image of the fetal liver (Figure 1) and calculates its volume. This was recorded and statistically analysed. All cases were then followedup until delivery and had their babies weighed within the first 24 hours and the actual birth weights recorded.

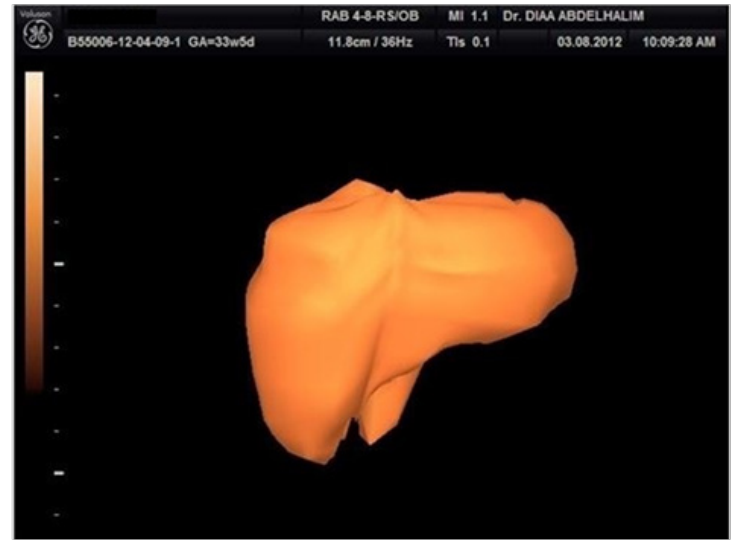

Figure I A 3D image of fetal liver by VOCAL at 33weeks and 5days of gestation.

Table I Percentage of increase between the $2^{\text {nd }}$ and $3^{\text {rd }}$ trimester measurements

\section{Statistical analysis}

Data were statistically described in terms of mean \pm standard deviation $( \pm \mathrm{SD})$ and range, or frequencies (number of cases) and percentages when appropriate. Paired t-test was used to compare quantitative variables, whereas correlation coefficient test ( $\mathrm{r}$ value) was used to rank variables positively or inversely. $\mathrm{P}$ values less than 0.01 were considered as highly significant, less than 0.05 were considered statistically significant, while $P$ values more than 0.05 were considered as statistically insignificant. All statistical calculations were done using computer programs SPSS (Statistical Package for the Social Science; SPSS Inc., Chicago, IL, USA) version 12 for Microsoft Windows.

\section{Results}

Normally developed fetuses were 273 out of 300 (91\%), growth restricted fetuses were 18 out of $300(6 \%)$ and large for gestational age fetuses were 9 out of $300(3 \%)$. The mean gestational age at delivery for normally developed fetuses was 38.25 weeks \pm 1.7 (SD) with a range of 34 to 42 weeks, while mean birth weight was $3081.5 \mathrm{~g} \pm 455$ with a range of 2150 to $4600 \mathrm{~g}$. Regarding the growthrestricted fetuses, the mean gestational age was 36.6weeks ranging from 34 to 39 weeks, and the mean birth weight was $1650 \mathrm{~g} \pm 95$ ranging from 1150 to $2100 \mathrm{~g}$. In large-for-gestational-age fetuses, the mean gestational age was 38.3 weeks ranging from 38 to 39 weeks, and the mean birth weight was $4466 \mathrm{~g} \pm 505$ ranging from 4300 to $4600 \mathrm{~g}$. The study showed that mean fetal liver volume was $20.03 \mathrm{~mL} \pm 5.1$ in the late $2^{\text {nd }}$ trimester (20-28weeks) with a range from 11.8 to $39.8 \mathrm{~mL}$ and $102 \mathrm{~mL} \pm 19.6$ in the late $3^{\text {rd }}$ trimester (34-40weeks) which ranged from 53.6 to $161 \mathrm{~mL}$. Mean head circumference was $206.9 \mathrm{~mm} \pm 19$ in the late $2^{\text {nd }}$ trimester (range from 169 to $253 \mathrm{~mm}$ ) and $316.6 \mathrm{~mm} \pm 16$ in the late $3^{\text {rd }}$ trimester (range from 275 to $368 \mathrm{~mm}$ ). Mean abdominal circumference was $176 \mathrm{~mm} \pm 19.8$ in the late $2^{\text {nd }}$ trimester (range from 139 to $237 \mathrm{~mm}$ ) and $307 \mathrm{~mm} \pm 25$ in the late $3^{\text {rd }}$ trimester (range from 228 to $384 \mathrm{~mm}$ ). While, mean femur length was $39.4 \mathrm{~mm} \pm 4.5$ in the late $2^{\text {nd }}$ trimester (range from 29.6 to $53.6 \mathrm{~mm}$ ) and $68 \mathrm{~mm} \pm 3.2$ in the late $3^{\text {rd }}$ trimester (range from 56.7 to $78 \mathrm{~mm}$ ) (Tables 1) (Table 2).

\begin{tabular}{lccccc}
\hline Variables & Baseline & After & \% of Change & T & P \\
\hline LV & $20.03 \pm 5.1$ & $102 \pm 19.6$ & $435 \pm 145$ & 42 & 0.0001 \\
& & & & & \\
HC & $206.9 \pm 19$ & $316.6 \pm 16$ & $54.5 \pm 14.6$ & 49 & 0.0001 \\
& & & & & \\
AC & $176 \pm 19.8$ & $307 \pm 25$ & $75.9 \pm 22$ & 12 & 0.0001 \\
& & & & & \\
FL & $39.4 \pm 4.5$ & $68 \pm 3.2$ & $74.9 \pm 21$ & 13 & 0.0001 \\
\hline
\end{tabular}

Citation: Torky H, Hegab M, Kamel M, et al.The Egyptian formula a new formula for prediction of fetal birth weight using liver volume measured by threedimensional ultrasound (VOCAL system). MOJ Womens Health. 20I7;4(2):25-28. DOI: I0.I5406/mojwh.20I7.04.00078 
Table 2 Correlation between $2^{\text {nd }} \& 3^{\text {rd }}$ trimester measures versus birth weight $\&$ Gestational age (G.A.)

\begin{tabular}{lllll}
\hline Variables & Birth weight & Birth weight & G.A. & G.A. \\
\cline { 2 - 5 } & $\mathbf{R}$ & $\mathbf{P}$ & $\mathbf{r}$ & $\mathbf{P}$ \\
\hline LV (2 ${ }^{\text {nd }}$ tri $)$ & 0.21 & 0.02 & 0.69 & 0.0001 \\
HC (2 ${ }^{\text {nd }}$ tri $)$ & 0.009 & 0.93 & 0.56 & 0.0001 \\
AC ( $2^{\text {nd }}$ tri $)$ & 0.03 & 0.76 & 0.66 & 0.0001 \\
FL (2 $2^{\text {nd }}$ tri $)$ & 0.008 & 0.94 & 0.78 & 0.0001 \\
LV (3 $3^{\text {rd }}$ tri $)$ & 0.57 & 0.0001 & 0.47 & 0.0001 \\
HC ( $3^{\text {rd }}$ tri $)$ & 0.81 & 0.0001 & 0.7 & 0.0001 \\
AC ( $3^{\text {rd }}$ tri $)$ & 0.75 & 0.0001 & 0.45 & 0.0001 \\
FL ( $3^{\text {rd }}$ tri $)$ & 0.68 & 0.0001 & 0.55 & 0.0001 \\
\hline
\end{tabular}

There was a statistically significant positive correlation between liver volume measured in the late $2^{\text {nd }}$ trimester and birth weight by using correlation coefficient test, while other measurements (HC, AC \& FL) showed statistically insignificant correlation. There was a statistically significant positive correlation between birth-weight versus different $3^{\text {rd }}$ trimester measures by using correlation coefficient test (Table 2). When using linear regression correlation between birth weight and liver volume was statistically significant (Beta error 2.7, $\mathrm{P}=0.0001$, C.I.(95\%) 10-23), the same high significance was found between birth weight and abdominal circumference (Beta error 3.6, $\mathrm{P}=0.0001$, C.I.(95\%) 18.7-29), however, the statistical significance was less - although still significant- when comparing between birth weight and femur length (Beta error 24, $\mathrm{P}=0.02$, C.I.(95\%) 7.4-105. There was a statistically significant positive correlation between gestational age versus different $2^{\text {nd }}$ and $3^{\text {rd }}$ trimester measures by using correlation coefficient test (Table 2). There was no statistically significant correlation between maternal age and any of the $2^{\text {nd }}$ trimester measures (LV: $\mathrm{r}=0.12, \mathrm{P}=0.33$ ), ( $\mathrm{HC}: \mathrm{r}=0.06, \mathrm{P}=0.55$ ), (AC: $\mathrm{r}=0.15, \mathrm{P}=0.38)$ and $(\mathrm{FL}: \mathrm{r}=0.08, \mathrm{P}=0.60)$. The same statistically insignificant correlation was found between maternal age and all $3^{\text {rd }}$ trimester measures (LV: $\mathrm{r}=0.05, \mathrm{P}=0.76)$, $(\mathrm{HC}: \mathrm{r}=0.03, \mathrm{P}=0.66)$, (AC: $\mathrm{r}=0.11, \mathrm{P}=0.40)$ and $(\mathrm{FL}: \mathrm{r}=0.02, \mathrm{P}=0.81)$.

Based on this significantly positive correlation (Figure 2), birth weight can be predicted from the late $2^{\text {nd }}$ trimester liver volume measurement using the following equation:

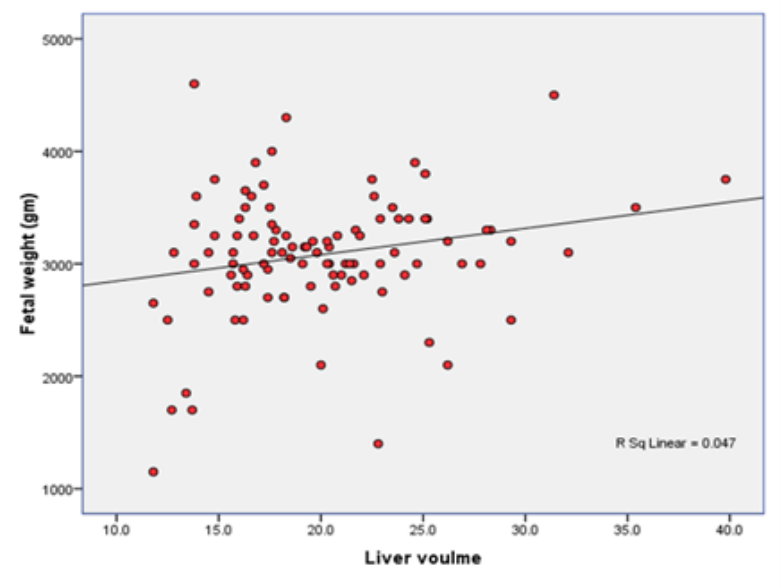

Figure 2 Regression analysis between liver volume and birth weight.
$\mathrm{W}=\mathrm{mL}+\mathrm{b}$

$\mathrm{W}=$ Birth Weight

$\mathrm{m}=200$ calculated by equation (slope)

$\mathrm{L}=$ any value of liver volume

$\mathrm{b}=$ intercept $=-14$

There was a statistically significant positive correlation between gestational age versus different measures by using correlation coefficient test (Table 2).

\section{Discussion}

Currently, ultrasound measurement of fetal head and upper abdominal circumference is the most widely used method of establishing impaired fetal growth, however, the detection of fetal growth restriction by means of head circumference measurement may be limited because of fetal brain sparing in the presence of chronic fetal hypoxemia. Several studies as ${ }^{7}$ and $^{8}$ have shown that the most effective method of detecting fetal growth restriction is the measurement of the upper abdominal circumference, however, this measurement is not satisfactory because the positive predictive value for detecting fetal growth restriction may be as low as $21 \%{ }^{9}$ Three-dimensional US measurements of the normal hepatic volume demonstrated a close linear relation between hepatic volume and estimated fetal weigh ${ }^{10,11}$ which was shown to contribute in the early detection of growth-restricted fetuses as hepatic weight is reduced due to reduction in hepatic glycogen stores. ${ }^{4}$ Chang and co-workers, 2006 revealed that fetal LV assessed by $3 \mathrm{D}$ ultrasound can differentiate between normal and growth restricted fetuses with a sensitivity of $97.6 \%$, a specificity of $93.6 \%$, a positive predictive value of $63 \%$, a negative predictive value of $99.7 \%$ and an accuracy of $94 \%$ concluding that fetal LV assessed by quantitative 3D ultrasound can be used for antenatal prediction of growth restricted fetuses. The current study demonstrated a five-fold increase in liver volume from $20.03 \pm 5.1 \mathrm{~mL}$ in the late $2^{\text {nd }}$ trimester $(20-28 \mathrm{wks})$ to $102 \pm 19.6 \mathrm{~mL}$ in the late $3^{\text {rd }}$ trimester (34-40 wks). Whereas, the increase was $1.5,1.7$ and 1.7 for $\mathrm{HC}, \mathrm{AC}$ and FL respectively between the two scans. In other terms, the percentage of change was $435 \%$ for $\mathrm{LV}, 54.5 \%$ for $\mathrm{HC}, 75.9 \%$ for $\mathrm{AC}$ and $74.9 \%$ for FL (Table 1), which makes it a more sensitive tool in detecting the eighteen cases of growth-restricted fetuses in our study. Simona and co-workers, ${ }^{12}$ found that normal fetal hepatic volume is ten-folds larger at the end of gestation, as compared with that at the beginning of the second half of pregnancy at 20 weeks a finding which 
can be considered consistent with the results of the current study if we put into account that the mean gestational age of the first scan was nearly 23 weeks. The current study also showed that $2^{\text {nd }}$ trimester liver volume was the only parameter to show a significant positive correlation with birth weight contrary to the $3^{\text {rd }}$ trimester parameters (LV, HC, AC and FL) which all showed this statistical significance (Table 2). Simona and co-workers, ${ }^{12}$ concluded that there is acceptable reproducibility of fetal liver volume, which shows a more pronounced reduction in growth restricted fetuses compared to head and upper abdominal circumference making it a better discriminator than head circumference. Based on the results of the current study an equation was generated to predict fetal birth weight using late $2^{\text {nd }}$ trimester liver volume, however, further studies are needed to test the accuracy of this equation and compare it with other currently used fetal birth weight equations.

\section{Conclusion}

Measurement of fetal liver volume may contribute to the early detection of fetal growth restriction as liver volume measurement in the late $2^{\text {nd }}$ trimester was found to be superior to $\mathrm{HC}, \mathrm{AC}$ and $\mathrm{FL}$ as a predictor for birth weight. Further studies are needed to test the accuracy of the newly generated equation using the second trimester liver volume in predicting birth weight and compare it to the currently used equations.

\section{Acknowledgements}

None.

\section{Conflict of interest}

The author declares no conflict of interest.

\section{References}

1. Gluckman PD, Hanson MA, Cooper C, et al. Effect of in utero and earlylife conditions on adult health and disease. N Engl J Med. 2008;359(1):6173.
2. Lubchenco LO, Hansman $\mathrm{C}$, Dressler M, et al. Intrauterine growth as estimated from liveborn birth-weight data at 24 to 42 weeks of gestation. Pediatr. 1968;32:793-800.

3. Campbell S, Wilkin D. Ultrasonic measurement of fetal abdomen circumference in the estimation of fetal weight. Br J Obstet Gynaecol. 1975;82(9):689-697.

4. Evans M, Mukherjee A, Schulman J. Animal models of intrauterine growth retardation. Obstet Gynecol Surv. 1968;38(4):183-192.

5. Vintzileos AM, Neckles S, Campbell WA, et al. Fetal liver ultrasound measurements during normal pregnancy. Obstet Gynecol. 1985;66(4):477480 .

6. Chang $\mathrm{CH}, \mathrm{Yu} \mathrm{CH}, \mathrm{Ko} \mathrm{HC}$, et al. Predicting fetal growth restriction with liver volume by three-dimensional ultrasound: Efficacy evaluation. Ultrasound Med Biol. 2006;32(1):13-17.

7. Seeds JW. Impaired fetal growth: ultrasonic evaluation and clinical management. Obstet Gynecol. 1984;64(4):577-584.

8. Warsof SL, Cooper DJ, Little D, et al. Routine ultrasound screening for antenatal detection of intrauterine growth retardation. Obstet Gynecol. 1986;7(1):33-39.

9. Baker PN, Johnson IR, Gowland PA, et al. Measurement of fetal liver, brain and placental volumes with echo-planer magnetic resonance imaging. $B r J$ Obstet Gynaecol. 1995;102(5):35-39.

10. Chang FM, Hsu KF, Ko HC, et al. Three-dimensional ultrasound assessment of fetal liver volume in normal pregnancy: a comparison of reproducibility with two-dimensional ultrasound and a search for a volume constant. Ultrasound Med Biol. 1997;23(3):381-389.

11. Laudy JA, Janssen MM, Struyk PC, et al. Fetal liver volume measurement by three-dimensional ultrasonography: a preliminary study. Ultrasound Obstet Gynecol. 1998;12(2):93-96.

12. Boito SM, Laudy JA, Struijk PC, et al. Three-dimensional US Assessment of hepatic volume, head circumference, and abdominal circumference in healthy and growth-restricted fetuses. Radiology. 2002;223(3):661-665. 